\title{
Encuadernaciones antiguas: sistemas para su estudio, difusión $y$ acceso en Internet
}

\author{
José Luis Herrera Morillas \\ Universidad de Extremadura (España)
}

\section{Resumen}

Localización, recopilación y análisis de treinta sistemas de información al servicio del estudio, difusión y acceso de encuadernaciones antiguas en Internet. Los recursos analizados han sido exposiciones virtuales, catálogos y bases de datos, pautas, glosarios, y otros recursos, que se presentan en el apéndice. Se ha definido un modelo de análisis para cada tipo de recurso. Entre ellos destacan la exposición virtual y el catálogo de Biblioteca de la Universidad Complutense, la base de datos de encuadernaciones de la British Library o la exposición virtual "Bound to Please: an Exhibition of Fine Leather Bindings" de la Universidad de Miami.

Palabras clave: Encuadernaciones. Libros antiguos. Sistemas de Información. Internet.

\begin{abstract}
Location, compilation and analysis of 30 information systems designed for ancient bookbindings in Internet: systems for its study, diffusion and access. The kind of resources are virtual exhibitions, catalogues and databases, guidelines, glossaries, and other resources, which are presented in an appendix. A model for the analysis of each type of resource has been designed. Some of the most interesting resources are the virtual exhibition and the catalogue of the Universidad Complutense Library, the database of bindings of the British Library or the virtual exhibition "Bound to Please: an Exhibition of Fine Leather Bindings" of the University of Miami.
\end{abstract}

Keywords: Bookbindings. Old books. Information Systems. Internet. 


\section{Introducción}

La aplicación de las Nuevas Tecnologías al libro antiguo lleva tiempo produciendo resultados de gran atractivo y utilidad. Los aspectos y elementos de este patrimonio bibliográfico que se han visto beneficiados de esa aplicación han ido aumentado y diversificándose. El trabajo que presentamos es un ejemplo de ello. En primer lugar porque aborda aspectos tan extendidos en la aplicación de las nuevas tecnologías como el diseño de recursos accesibles a través de Internet y la aplicación de la digitalización. Y en segundo, por estar dedicado a un elemento particular del libro antiguo: las encuadernaciones artísticas. Estas piezas tan singulares y valoradas de nuestros libros son mucho más que un elemento protector, pues han sido confeccionadas con la intención y los procedimientos propios de la creación artística para que "cada libro sea un ejemplar único, donde el artesano encuadernador ha puesto todo su cariño, habilidad e imaginación en el diseño, construcción y decoración de la obra" (Berzosa, 2005).

Nuestra intención ha consistido en localizar, recopilar y analizar sistemas de información al servicio del estudio, difusión y acceso de encuadernaciones antiguas disponibles en Internet. Entendiendo por sistema de información (Rodríguez y Ronda, 2006):

Un conjunto de elementos relacionados y ordenados, según ciertas reglas que aporta al sistema objeto - es decir, a la organización a la que sirve y que marca sus directrices de funcionamiento - la información necesaria para el cumplimiento de sus fines; para ello, debe recoger, procesar y almacenar datos, procedentes tanto de la organización como de fuentes externas, con el propósito de facilitar su recuperación, elaboración y presentación.

Con este estudio hemos querido realizar un instrumento que sirva de ayuda a las personas interesadas en el arte ligatorio, y a la vez contribuir a su conocimiento y difusión, ya que, como ha expresado Deveaux (2003, p. 12), las encuadernaciones de arte son a menudo unas grandes desconocidas:

Son muchas las personas que ya han admirado los trabajos de joyería, los bellos encajes, las esculturas sobre madera, las porcelanas y otras obras salidas de las manos de artesanos diversos; por el contrario, las bellas encuadernaciones tan solo han sido conocidas y amadas por un grupo muy reducido de coleccionistas y aficionados. Esta situación es a todas luces injusta.

También nos ha motivado el hecho de que los grupos de usuarios de las estructuras tradicionales de bibliotecas, archivos y museos se han redefinido por el creciente uso de Internet: "Los investigadores crean o utilizan recursos electrónicos para llevar a cabo sus investigaciones; los modelos de enseñanza a distancia urgen a los profesores a reunir recursos web en un entorno de enseñanza en línea" (Directrices..., 2005, p. 64). 


\section{Metodología}

Para localizar los sistemas y recursos relacionados con las encuadernaciones antiguas utilizamos los buscadores más empleados en Internet, también procedemos a la consulta de los sitios web de las bibliotecas e instituciones depositarias de importantes colecciones de encuadernaciones. Una vez finalizada la búsqueda, el paso siguiente consiste en la clasificación estableciendo estos tipos: Exposiciones y muestras, Catálogos y bases de datos, Directrices, Glosarios, Otros.

En la tercera fase procedemos al análisis. Para ello establecemos un esquema adaptado a cada tipo. En las exposiciones y muestras nos fijamos en la temática, idioma, institución organizadora, si existe o no relación con una exposición presencial, contenido (volumen de obras expuestas, organización temática, etc.), diseño (estilo y diseño de la web, forma de estructurar los contenidos, presentación y acceso a los imágenes de las encuadernaciones, a los textos y referencias de las piezas expuesta, etc.). Con todo ello elaboramos registros formados por estos elementos: título, URL, lengua, fecha de consulta, institución organizadora, contenido, diseño. Para los catálogos y bases de datos prestamos atención a las características más destacables de los mismos, tales como los documentos e información que contienen; el tipo de registros elaborados para la descripción de las obras; el sistema de acceso y recuperación de los objetos. Los registros elaborados presentan esta información: nombre, URL, lengua, fecha de consulta, institución, contenido, tipo de registros, sistema de acceso. Para las directrices y otros recursos: nombre, URL, lengua, fecha de consulta, contenido.

\section{Resultados}

De los 28 sistemas y recursos localizados corresponden a los distintos tipos los siguientes: 17 a exposiciones y muestras virtuales, 4 a catálogos y bases de datos, 1 a directrices, 2 a glosarios y 4 a otros. En función del tipo de centros que los han organizado, 25 corresponden a bibliotecas (11 universitarias, 9 nacionales, 3 especializadas, 1 pública y 1 a varias bibliotecas de distintos tipos) y 3 a otras instituciones culturales. Respecto a los idiomas en los que los recursos han sido redactados, los datos son los siguientes: 20 en inglés, 2 en francés, 2 en alemán, 3 en castellano y 1 en otros idiomas. En el apéndice I se relacionan y analizan todos los recursos recopilados.

\section{Conclusiones}

El trabajo realizado ilustra el impacto de las nuevas tecnologías en el entorno del libro antiguo por medio de los recursos analizados, ejemplos de buenas prácticas en el campo de las bibliotecas y del patrimonio bibliográfico: los sistemas de información que han diseñado se encuentran al alcance de todos los públicos 
por medio de Internet "así se crean las bases de un nuevo modelo, en el que los usuarios interactúan directamente con los sistemas de información para satisfacer sus necesidades de información" (Rodríguez y Ronda, 2006).

También hemos comprobado cómo es una realidad consolidada que en la mayoría de los sistemas y recursos está presente la digitalización, ya que entre otros beneficios "proporciona un acceso mas amplio y fácil, la conservación de los originales, la posibilidad de sumar valor añadido a las imágenes y colecciones" (Pautas Calimera..., 2005). El hecho de que hasta de un aspecto tan particular del libro antiguo como son las encuadernaciones exista un grupo notable de recursos refleja que (Directrices..., 2005, p. 8):

Internet es el lugar de mercado para la investigación, la enseñanza, la expresión, la publicación y la comunicación de la información. Las bibliotecas y los archivos son proveedores de información primaria para la sociedad y fueron usuarios de la nueva tecnología digital primero en relación con la catalogación y la gestión de los procesos, y más tarde para proporcionar información sobre sus colecciones a la comunidad de la WWW.

Los recursos más extendidos son las exposiciones virtuales y casi todas las que hemos localizado están concebidas con unos criterios "clásicos" que responden más bien a un catálogo virtual. Hoy en día se ha avanzado en el diseño de las exposiciones virtuales y, sobre todo, cuando van paralelas a las presenciales, están incorporando una mayor interactividad, casi siempre en relación con los planos o imágenes de la exposición presencial, por ejemplo con soluciones que nos permiten seleccionar los objetos marcados en el plano y verlos con más detalle. Estos planos y/o fotos también permiten actuar de "ventana" que nos pone en contacto con la muestra presencial saltando las barreras espacio-temporales.

Junto a la interactividad se están incorporando elementos de audio y vídeo: las exposiciones virtuales más recientes se caracterizan por incluir elementos sonoros y vídeos con imágenes de la exposición presencial o con contenidos complementarios de la muestra. Estos elementos, junto al tipo de interactividad descrita, son los que echamos en falta en las exposiciones recopiladas.

\section{Referencias}

Berzosa Alonso-Martínez, C. (2005). Presentación. // Encuadernaciones en la Biblioteca Complutense. URL: <http://www.ucm.es/BUCM/foa/exposiciones/ 14Encuadernaciones/index.htm>. Consultado: 2006-09-22.

Devaux, I. (2003). Prólogo. // Checa Cremades, J. L. Los estilos de encuadernación. Madrid: Ollero/Ramos. 12-13.

Directrices para proyectos de digitalización de colecciones y fondos de dominio público, en particular para aquellos custodiados en bibliotecas y archivos: marzo de 2002 (2005). Madrid: Ministerio de Cultura, Secretaría General Técnica. 
Pautas CALIMERA de buena práctica (2005). URL: <http://www.calimera.org/Countries/ Spain.aspx>. Consultado: 2006-09-22.

Rodríguez Perojo, K.; Ronda León, R. (2006). El Web como sistema de información. // Acimed, 14 (1) 2006. URL: <http://bvs.sld.cu/revistas/aci/vol14_1_06/ aci08106.htm>. Consultado: 2006-09-22.

\section{Apéndice I: Recursos analizados}

\section{Exposiciones y muestras virtuales}

Arte della legatura a Brera

URL: http://www.braidense.it/bookbinding/index.html

Lenguas: italiano, inglés, alemán y francés.

Fecha de consulta: 25/09/06.

Institución organizadora: Biblioteca Brera, Milán.

Contenido: Se muestra una selección de las encuadernaciones relativas a los siglos XV al XVI que formaron parte de la exposición Arte della legatura a Brera en la citada biblioteca, que tuvo lugar del 18 e abril al 22 de junio de 2002. Las ilustraciones tienen su origen en el proyecto experimental de reproducción digital iniciado en 1994. En total se incluyen 131 ilustraciones de encuadernaciones: 16 del siglo XV, 35 italianas del siglo XVI, 23 italianas del siglo XVI, 16 francesas del siglo XVI, 23 alemanas del siglo XVI, 3 españolas del siglo XVI, 5 de varios lugares del siglo XVI, 10 de la biblioteca del bibliófilo Jean-Baptiste Colbert.

Diseño: En primer lugar aparece una página de inicio con el nombre de la biblioteca, los idiomas que se pueden seleccionar, un menú de contenidos complementarios: ayuda, noticias, estudios, links, enlace a la Biblioteca Braidense y 2 ilustraciones de encuadernaciones. La exposición está formada por un texto explicativo sobre el origen de este recurso, y debajo pequeñas ilustraciones de encuadernaciones que actúan de acceso a las 8 secciones cronológicas en las que se organiza la exposición. También se dedican apartados a los materiales y utensilios relacionados con la técnica de la encuadernación. Cada sección está formada por las ilustraciones en pequeño formato, y menús para visualizar textos explicativos, para avanzar y para volver al índice. Al pulsar cada imagen se amplía, y va acompañada de botones para abrir el texto o ficha explicativa, ampliar a un formato mayor, avanzar o volver al inicio.

\section{Biblioteca Mazarina (encuadernaciones)}

URL: http://www.bibliotheque-mazarine.fr/

Lengua: francés.

Fecha de consulta: 24/09/06.

Institución organizadora: Biblioteca Mazarina, París.

Contenido: Es un apartado de la web de la biblioteca que informa sobre las encuadernaciones antiguas que conserva la biblioteca. Se muestran 4 encuadernaciones con varias ilustraciones de cada una y una completa descripción.

Diseño: En la sección "Tresaures" de la web se incluye un apartado para las encuadernaciones "preciosas". Las imágenes se presentan en formato reducido y se pueden visualizar en pantallas independientes.

Scire. $11: 1$ (en.-jun. 2005) 123-135. ISSN 1135-3761. 


\section{José Luis Herrera Morillas}

\section{Book bindings and design}

URL: http://www.kb.nl/galerie/100hoogtepunten/boekbanden-en.html

Lengua: inglés.

Fecha de consulta: 25/09/06.

Institución organizadora: Biblioteca Nacional de los Países Bajos.

Contenido: Exposición virtual que exhibe una selección de 14 piezas ligatorias con textos descriptivos e ilustraciones.

Diseño: La primera página está concebida como un collage con fragmentos de las distintas encuadernaciones acompañadas de la referencia descriptiva. Cada fragmento da acceso a una página con la ilustración de la pieza, la referencia completa y un texto explicativo.

\section{Bookbindings}

URL: http://www.kb.nl/bc/boekb/boekb-en.html

Lengua: inglés.

Fecha de consulta: 25/09/06.

Institución organizadora: Biblioteca Nacional de los Países Bajos.

Contenido: Exposición con apartados dedicados a encuadernaciones holandesas, encuadernaciones extranjeras, encuadernaciones especiales y elementos relacionados con la encuadernación. En total se visualizan 21 encuadernaciones.

Diseño: Se concibe mediante páginas enlazadas; cada página es un apartado de la muestra. Todas presentan un diseño común: texto, acompañado en el margen derecho por las ilustraciones, que se pueden visualizar en pantallas independientes, en un tamaño mayor.

Bookbindings in paper and clot, 1800-1925

URL: http://library.queensu.ca/webmus/exhibits/2004mar_bookbindings.htm

Lengua: inglés.

Fecha de consulta: 21/08/06.

Institución organizadora: Jordan Special Collections \& Music Library, Kingston, Canadá.

Contenido: Página de promoción de la exposición presencial celebrada en marzo de 2004. Se incluyen los datos de la muestra, un texto explicativo del contenido ilustrado con 4 encuadernaciones.

Diseño: En una sola página se reúne toda la información: datos de celebración y el texto con las ilustraciones intercaladas.

\section{Bound to Please: Fine Leather Bindings}

U.R.L: http://scholar.library.miami.edu/bound/

Lengua: inglés.

Fecha de consulta: 01/11/06.

Institución: University of Miami.

Contenido: Exposición dedicada a mostrar una selección de 70 encuadernaciones de la Universidad de Miami. Se describen e ilustran un grupo de encuadernaciones del siglo XV hasta el XX, de libros realizados en Estados Unidos, Cuba, España, Francia, Alemania, Italia y Holanda. 
La exposición destaca los intrincados procesos técnicos requeridos para producir estas encuadernaciones. Se ilustran las diversas técnicas y estilos. En total se incluyen 38 imágenes de las encuadernaciones.

Diseño: Se inicia con una página índice, decorada en la parte superior con varias imágenes de encuadernaciones. Las obras del catálogo se distribuyen en una sola página, organizado en forma de listado, en distintos apartados temáticos según los diferentes tipos de encuadernación.

Cada uno de los apartados reúne información sobre la técnica o el tipo de encuadernación a la que se dedica, referencias bibliográficas de las obras (autor, título, lugar de publicación, editor, año, páginas, dimensiones y notas) y comentarios sobre la encuadernación de cada ejemplar. Las imágenes se pueden ampliar. Otros elementos que contiene: selección bibliográfica; índice de encuadernadores (ordenados alfabéticamente y haciendo referencia al número secuencial de las obras); índice cronológico (las obras ordenadas por años); adenda, con seis obras añadidas a la exposición, de las que se indican los mismos datos. Incluye también enlaces a archivos y colecciones especiales, a la Biblioteca Otto G. Richter y a la Universidad de Miami.

The bookbindings in the Koopman Collection

URL: http://www.kb.nl/bc/koopman/overdecollectie/d05-en.html

Lengua: inglés.

Fecha de consulta: 23/08/06.

Institución organizadora: Biblioteca Nacional de los Países Bajos.

Contenido: Texto explicativo acompañado de 9 ilustraciones que se pueden ampliar.

Diseño: En una página se incluye el texto, acompañado en el margen derecho de las ilustraciones, que se pueden visualizar en pantallas independientes y a mayor tamaño.

British Bookbindings, 16th-19th century

URL: http://special.lib.gla.ac.uk/exhibns/bindings/index.html

Lengua: inglés.

Fecha de consulta: 12/09/06.

Institución organizadora: University of Glasgow Library.

Contenido: Exposición celebrada en la Hunterian Library de la University of Glasgow en diciembre de 1970 y disponible en versión electrónica a partir de diciembre de 1999. En total hay accesibles 55 imágenes.

Diseño: Estructurada en una sola página donde se suceden las referencias de las obras y las ilustraciones en pequeño formato, que se pueden ampliar. Al inicio de la web existen 4 formularios de búsqueda correspondientes a los siglos XVI, XVII, XVII y XIX, y dentro de cada uno se ofrece una lista de encuadernadores. Este procedimiento se corresponde con el criterio con el que se organizan las piezas.

British Library, International Dunhuang Project

URL: http://idp.bl.uk/education/bookbinding/bookbinding.a4d

Lengua: inglés.

Fecha de consulta: 26/09/06.

Institución organizadora: British Library.

Scire. $11: 1$ (en.-jun. 2005) 123-135. ISSN 1135-3761. 
Contenido: Descripción de las encuadernaciones chinas conservadas en esta institución. Es una sección del Proyecto Internacional Dunhuang. Se accede a través del apartado principal, "Education".

Diseño: Este recurso está formado solo por una página con un índice en la parte superior que enlaza a los distintos apartados dentro de la misma página. Se organiza en 8 apartados: uno dedicado a las características de los libros de la colección, 6 donde se ilustran y explican con detalle los diferentes tipos de encuadernaciones y otro para bibliografía. En los textos se intercalan ilustraciones que se pueden ampliar.

Century bindings from the Royal Libraries of France featured in Renaissance Bindings for Henri II

URL: http://www.nypl.org/press/2002/renaissancebindings.cfm

Lengua: inglés.

Fecha de consulta: 21/10/06.

Institución organizadora: New York Public Library.

Contenido: Página de promoción de la exposición que tuvo lugar en esta biblioteca desde el 15 de noviembre de 2002 hasta el 8 de febrero de 2003, en la que se mostró una selección de 26 encuadernaciones del siglo XVI de las bibliotecas reales de Francia.

Diseño: La página está formada por un texto y las ilustraciones de 2 encuadernaciones.

\section{Encuadernaciones en la Biblioteca Complutense}

URL: http://www.ucm.es/BUCM/foa/exposiciones/14Encuadernaciones/index.htm Lengua: castellano.

Fecha de consulta: 26/09/06.

Institución organizadora: Biblioteca Histórica Marques de Valdecilla (Universidad Complutense de Madrid).

Contenido: Es la versión digital de la exposición que tuvo lugar en esta biblioteca del 18 de enero al 11 de marzo de 2005. Se exponen más de 18 encuadernaciones de sus fondos. Diseño: Página de presentación a modo de portada con el título y los datos de la exposición presencial. Un índice da acceso a los diferentes apartados de la muestra ("Introducción". "De las primeras encuadernaciones al mudéjar". "El estilo gótico". "Un estilo genuinamente español: el plateresco". "El Renacimiento en Centroeuropa". "Impulsores del Renacimiento: Aldo Manucio y Jean Grolier". "El Siglo de Oro de la encuadernación española". "El estilo barroco y sus variantes". "Dos ejemplos singulares: el estilo de abanicos y à la Duseuil". "El barroco francés: à la Fanfare y le Gascon". "El predominio de los estilos franceses en el siglo XVIII". "Del recargamiento a la sencillez de las formas clásicas". "Los siglos XIX y XX". "Emblemas de las armas reales de Francia". "Emblemas de las armas reales de España". "Emblemas eclesiásticos". "Emblemas nobiliarios". "Emblemas de diversa procedencia"). En cada apartado se incluye un texto y una ilustración. También dispone de un enlace a la "Colección de encuadernaciones en el catálogo de la Biblioteca Complutense", es decir, a todos los registros de los libros del catálogo, que incluye una ilustración de la encuadernación.

\section{Hand Bookbindings: Plain and Simple to Grand and Glorious}

URL: http://libweb5.princeton.edu/visual_materials/hb/index.html

Lengua: inglés.

Scire. $11: 1$ (en.-jun. 2005) 123-135. ISSN 1135-3761. 
Fecha de consulta: 22/09/06.

Institución organizadora: Princeton University Library.

Contenido: Exposición virtual relacionada con la exposición presencial del mismo nombre celebrada en esta biblioteca del 10 de noviembre de 2002 al 20 de abril de 2003. En total se exhiben 211 encuadernaciones.

Diseño: En la página de inicio se visualiza una tabla con 26 imágenes de encuadernaciones en pequeño formato que dan acceso a los 26 grupos en los que se organizan las 211 encuadernaciones que forman el conjunto de la muestra y, debajo, un texto introductorio. Cada grupo muestra un texto explicativo y registros de las piezas con los campos de los datos descriptivos (autor, título, impresor, localización, signatura y dimensiones del lomo) y una ilustración que se puede ampliar en una nueva pantalla con distintas opciones para visualizar detalles del objeto.

Judging a Book by Its Cover - Gold-Stamped Publishers' Bindings of the 19th Century. Exhibition

URL: http://www.columbia.edu/cu/lweb/eresources/exhibitions/gilded/index.html\#more Lengua: inglés.

Fecha de consulta: 22/09/06.

Institución organizadora: Columbia University Library, Nueva York.

Contenido: Exposición celebrada del 14 de noviembre de 1997 al 27 de febrero de 1998 en la Kempner Gallery. Se presentan 243 encuadernaciones estampadas en oro del siglo XIX, organizadas en 13 apartados.

Diseño: Consta de una página de inicio con los datos de la exposición y un texto introductorio. En la parte derecha está el menú para acceder a los 13 apartados. En cada apartado se presenta un breve texto explicativo y las ilustraciones de las obras en pequeño formato, que se pueden ampliar en una nueva pantalla acompañada de la referencia bibliográfica. También incluye una bibliografía. La página de inicio muestra en la parte superior el logotipo-enlace a la "Rare Book \& Manuscript Library" y a la "Columbia University Library", así como el menú de esta.

Leather and vellum bookbindings 1500 to 1920 Queen's

URL: http://library.queensu.ca/webmus/sc/exhibitsarch3.html

Lengua: inglés.

Fecha de consulta: 11/10/06.

Institución organizadora: University Libraries, Kingston, Canadá.

Contenido: Página divulgativa de la exposición presencial celebrada del 29 de junio al 12 de marzo de 2002.

Diseño: Solamente una página para informar de la exposición con un texto que intercala 12 ilustraciones de las encuadernaciones.

Reliures françaises du XVIIe siècle: exposition au musée Condé

URL: http://www.institut-de-france.fr/patrimoine/chantilly/reliures.htm

Lengua: francés.

Fecha de consulta: 22/09/06.

Institución organizadora: Institut de France.

Scire. $11: 1$ (en.-jun. 2005) 123-135. ISSN 1135-3761. 
Contenido: Exposición de encuadernaciones francesas del siglo XVII, celebrada del 24 abril al 23 de septiembre de 2002 en "le Cabinet des livres du duc d'Aumale". Solo incluye texto e imágenes de dos encuadernaciones: una, ejemplo de las encuadernaciones "à grand décor (1615-1665)", y otra del tipo "Reliures pour des curieux (1690-1710)".

Diseño: En una única página se incluye el texto con las imágenes intercaladas, que se pueden ver en pantalla aparte al pulsarlas. En el encabezamiento de la página está el logotipo y el menú del Institut de France.

\section{Scottish Decorative Bookbinding}

URL: http://www.nls.uk/digitallibrary/bookbinding/

Lengua: inglés.

Fecha de consulta: 22/09/06.

Institución organizadora: The National Library of Scotland.

Contenido: Exposición virtual de la colección de encuadernaciones artísticas de la Biblioteca Nacional de Escocia que abarca piezas de cinco siglos. En total se muestran 81 encuadernaciones de los siglos XVII al XIX.

Diseño: La web se organiza en una introducción y en el catálogo dividido en 4 apartados cronológicos (1600-1729; 1730-1750; 1751-1769; 1770-1810). Dentro de cada apartado se recogen ilustraciones de las encuadernaciones en tamaño reducido (se pueden visualizar en pantallas independientes) acompañadas de los datos descriptivos. La página de presentación la forman un texto sobre la biblioteca, la imagen de una encuadernación y el índice de acceso a las partes de la muestra.

Victorian Bookbindings: innovatio and extravagance 1820-1910

URL: http://www.library.unt.edu/rarebooks/exhibits/binding/default.htm Lengua: inglés.

Fecha de consulta: 21/09/06.

Institución organizadora: University of North Texas Library.

Contenido: Versión digital de la muestra celebrada desde el 1 de abril hasta el 30 de septiembre de 2000 en la sección de libros raros de esta Biblioteca. Se muestran ilustraciones de más de 50 encuadernaciones.

Diseño: En primer lugar se visualiza una página a modo de portada con los datos de la muestra y algunas imágenes de las piezas. Incluye el menú con las opciones para acceder a los objetos: visita por periodos cronológicos, visita por temas. Además cuenta con una introducción y un apartado denominado "Catálogo" en el que aparecen las referencias de todas las obras exhibidas en la exposición presencial. Las referencias de las obras mostradas en la versión virtual actúan de hiperenlaces a las imágenes.

Las páginas con las encuadernaciones están formadas por ilustraciones de las obras, que se pueden ampliar, acompañadas de las referencias descriptivas.

\section{Catálogos y bases de datos}

British Library Integrated Catalogue

URL: http://catalogue.bl.uk/F/?func=file\&file_name=login-bl-list

Lengua: inglés.

Fecha de consulta: 29/09/06. 
Institución: British Library.

Contenido: Pantalla con la explicación para realizar búsquedas en el catálogo integrado de la British Library, a través del cual se puede acceder también a las encuadernaciones digitalizadas.

Tipo de registros: Con etiquetas para los campos propios de un web-catálogo.

Sistema de acceso: Permite búsquedas básicas y búsquedas avanzadas.

British Library-Database of Bookbindings

URL: http://prodigi.bl.uk/bindings/welcome.htm

Lengua: inglés.

Fecha de consulta: 28/09/06.

Institución: British Library.

Contenido: Esta base de datos incluye información e imágenes de una selección de piezas de la colección de encuadernaciones ricas de la British Library, pertenecientes a libros impresos en Europa occidental a partir del siglo XV. Es un proyecto en curso.

Tipo de registros: Cada registro incluye una imagen de tamaño medio, que se puede ampliar a un tamaño superior al de la pantalla, y los datos catalográficos (incompletos en muchas ocasiones).

Sistema de acceso: Se ha diseñado con las siguientes opciones: visualizar una selección de las encuadernaciones a través de la opción "the picture gallery"; por palabras clave; por categorías a través de la opción "búsqueda simple"; mediante la opción "búsqueda avanzada”, que combina varias categorías. Incluye un apartado para bibliografía.

Catálogo Cisne, Universidad Complutense de Madrid

URL: http://cisne.sim.ucm.es/

Lengua: castellano.

Fecha de consulta: 24/09/06.

Institución: Biblioteca Universidad Complutense de Madrid.

Contenido: Encuadernaciones del fondo antiguo de la Biblioteca Histórica Marqués de Valdecilla de esta Universidad.

Tipo de registros: Archivos en PDF con la imagen digitalizada de la encuadernación y su descripción, con estos elementos: estilo y nombre identificativo, fecha, dimensiones, procedencia, materiales utilizados, técnicas de encuadernación, decoración y estado de conservación.

Sistema de acceso: Se accede a través del catálogo general de la Universidad. Algunos registros incluyen un campo para acceder al archivo en PDF con la imagen de la encuadernación y su descripción.

Einbanddatenbank

URL: http://www.hist-einband.de/

Lengua: alemán.

Fecha de consulta: 23/09/06.

Institución: varias bibliotecas.

Contenido: Base de datos de imágenes digitalizadas de motivos ornamentales de las encuadernaciones conservadas en las colecciones de la Staatsbibliothek zu BerlinPreussischer Kulturbesitz, la Württembergische Landesbibliothek Stuttgart, la Herzog

Scire. $11: 1$ (en.-jun. 2005) 123-135. ISSN 1135-3761. 
August Bibliothek Wolfenbüttel y la Bayerische Staatsbibliothek Munich. Es un trabajo en curso.

Tipo de registros: Los registros se organizan en campos y se acompañan de una imagen del motivo.

Sistema de acceso: La base de datos permite recuperar la información por distintos campos: lugar, biblioteca, motivos, etc. Se completa con información sobre el proyecto, tesauros especializados y ayuda.

Publishers' Bindings Online 1815-1930

URL: http://bindings.lib.ua.edu/

Lengua: inglés.

Fecha de consulta: 26/09/06.

Institución: University of Alabama.

Contenido: Base de datos que contiene 4.526 libros y 10.570 imágenes.

Tipo de registros: Diseñados meditante etiquetas, presentan dos opciones, versión breve: imagen, título, fecha, lugar, materias y derechos de autor; versión amplia, además de los datos anteriores, añade autor, editor, descripción, lengua, tipo, formato, signatura, colección, identificación local e imágenes de la tapa y el lomo de la encuadernación con varias opciones de visualización.

Sistema de acceso: Se puede buscar por palabra clave, por términos de una lista dada, por 27 galerías temáticas, diseñadas a modo de exposición virtual con las imágenes (ampliables) intercaladas entre el texto que las va comentando.

La base de datos se completa con información sobre el proyecto, las bibliotecas o el mapa del sitio.

\section{Directrices}

Guidelines for the conservation of leather and parchment bookbindings (The National Library of the Netherlands)

URL: http://www.kb.nl/cons/leather/index-en.html

Lengua: inglés.

Fecha de consulta: 23/08/06.

Contenido: Consta de estos apartados: 1. Descripción de la fabricación de la piel y el pergamino. 2. Examen sucinto de los tratamientos de conservación. 3. Causas y fenómenos del deterioro de la piel y el pergamino. 4. Categorías y tratamiento de los daños. 5. Procedimientos y fórmulas para la conservación de encuadernaciones de piel y tratamientos específicos para los tipos de daños. 6. Procedimientos y fórmulas para la conservación de encuadernaciones de pergamino. 7. Pruebas analíticas. 8. Documentación. 9. Almacenamiento y organización. 10. Lista de fórmulas. 11. Breve bibliografía.

\section{Glosarios}

Bookbinding and the Conservation of Books: A Dictionary of Descriptive Terminology

URL: http://palimpsest.stanford.edu/don/don.html

Lengua: inglés.

Fecha de consulta: 26/08/06. 
Contenido: Versión digital de la obra de Matt T. Roberts and Don Etherington. Bookbinding and the Conservation of Books: A Dictionary of Descriptive Terminology, Washington, D.C.: Library of Congress, 1982.

Glossary of binding terms (University of Florida)

URL: http://www.uflib.ufl.edu/preserve/binding/glossary.htm

Lengua: inglés.

Fecha de consulta: 23/08/06.

Contenido: Vocabulario sobre encuadernación.

\section{Otros recursos}

Conservación de material bibliográfico y documental. Restauración de encuadernaciones

URL: http://xlpv.cult.gva.es/files/conservacion $\% 20 \mathrm{de} \% 20$ material.pdf\#search $=\% 22 \mathrm{encu}$ adernaciones $\% 20$ conservaci\%C3\%B3n\%22

Lengua: castellano.

Fecha de consulta: 26/08/06.

Contenido: Fotografías sobre el proceso de conservación y restauración de encuadernaciones.

Einbände und Buchbinder (Universitätsbibliothek Graz)

URL: http://www.kfunigraz.ac.at/ub/sosa/einband/index.html

Lengua: alemán.

Fecha de consulta: 26/08/06.

Contenido: Documentos y textos explicativos para descargar sobre los motivos ornamentales de las encuadernaciones.

Guide to bookbindings in the British Library

URL: http://www.bl.uk/collections/early/bindingsguide1.html

Lengua: inglés.

Fecha de consulta: 26/08/06.

Contenido: Recurso explicativo e introductorio a modo de ayuda sobre las colecciones de encuadernaciones de la British Library. Está organizado en 5 partes: introducción, colecciones especiales (que incluyen las encuadernaciones), buscador de encuadernaciones, colección de referencia sobre encuadernaciones, literatura básica sobre encuadernaciones y modo de descripción de las encuadernaciones.

Metropolitan Museum of Art, New York

URL: http://www.metmuseum.org/toah/splash.htm

Lengua: inglés.

Fecha de consulta: 26/08/06.

Contenido: A través del formulario de búsquedas de esta web se pueden recuperar los registros dedicados a encuadernaciones artísticas. De cada una se incluyen una ilustración, que se puede ampliar, datos descriptivos y texto explicativo.

Scire. $11: 1$ (en.-jun. 2005) 123-135. ISSN 1135-3761. 